\title{
Exploring changes in middle-school student lunch consumption after local school food service policy modifications
}

\author{
Karen Weber Cullen ${ }^{1, *}$, Kathy Watson ${ }^{1}$, Issa Zakeri ${ }^{1}$ and Katherine Ralston ${ }^{2}$ \\ 'Children's Nutrition Research Center, Department of Pediatrics, Baylor College of Medicine, 1100 Bates Street, \\ Houston, TX 77030-2600, USA: ${ }^{2}$ Economic Research Service, US Department of Agriculture, 1800 M Street NW \\ Room N2183, Washington, DC 20036-5831, USA
}

Submitted 30 December 2004: Accepted 14 September 2005

\begin{abstract}
Objective: This study assessed the impact of changes in school food policy on student lunch consumption in middle schools.

Methods: Two years of lunch food records were collected from students at three middle schools in the Houston, Texas area. During the first year, no changes occurred in the school food environment. After that school year was completed, chips and dessert foods were removed from the snack bars of all schools by the Food Service Director. Students recorded the amount and source of food and beverage items consumed. Point-of-service purchase machines provided a day-by-day electronic data file with food and beverage purchases from the snack bars during the 2-year period. Independent $t$-tests and time series analyses were used to document the impact of the policy change on consumption and sales data between the two years. Results: In general, student consumption of sweetened beverages declined and milk, calcium, vitamin A, saturated fat and sodium increased after the policy change. Snack chips consumption from the snack bar declined in year 2; however, consumption of snack chips and candy from vending increased and the number of vending machines in study schools doubled during the study period. Ice cream sales increased significantly in year 2 .

Conclusions: Policy changes on foods sold in schools can result in changes in student consumption from the targeted environments. However, if all environments do not make similar changes, compensation may occur.
\end{abstract}

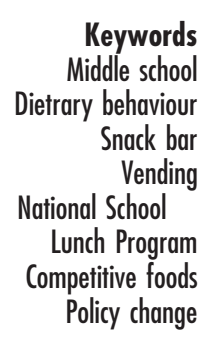

National School Lunch Program (NSLP) meals are offered daily to about $95 \%$ of children in the $\mathrm{USA}^{1,2}$. Concerns about the epidemic of overweight and obesity in the USA ${ }^{3}$ have focused attention on the types of foods available in the school environment ${ }^{4}$, because the environment is an important influence on dietary behaviour as identified in Social Cognitive Theory $(\mathrm{SCT})^{5}$. SCT proposes that behaviour, personal characteristics and the environment each influence, and are influenced in, a reciprocal relationship 5 . For example, the availability of fruit and vegetables $(F \& V)$ in the school cafeteria was a significant predictor of $\mathrm{F} \& \mathrm{~V}$ consumption following a 2-year intervention $^{6}$. Therefore, improvements to the types of foods available in the school environment could have an impact on student consumption.

Since 1994, NSLP meals must average $30 \%$ or less of their energy from fat and most serve two or more F\&V items daily $^{7}$. However, there are no federal rules for competitive foods sold elsewhere in the school such as in snack bars and vending machines (VMs), and over $80 \%$ of middle schools sell à la carte food items ${ }^{8}$. Weekly sales ranged from $\$ 826$ per 1000 students in schools with $72-100 \%$ of students receiving free/reduced-price meals, to $\$ 2894$ per 1000 students from schools with less than $38 \%$ of students eligible for free/reduced-price meals ${ }^{8}$. Weekly à la carte sales were inversely related to NSLP participation ${ }^{8}$. The median number of VMs per secondary school was 12 (four offering soft drinks, two snacks, five other) in another study, and only $35 \%$ of the foods in VMs met a lower-fat criterion $\left(\leq 5.5 \mathrm{~g}\right.$ fat per serving) ${ }^{9}$. Snack VMs were negatively related to daily fruit consumption among middle-school youth ${ }^{10}$.

Few published studies identify actual lunch food consumption by middle-school youth from these various sources at school. Students who reported eating the NSLP meal consumed greater amounts of all nutrients, except vitamin C, compared with students who reported eating lunch meals from home, restaurants and other sources ${ }^{11}$. National data also revealed that youth participating in the NSLP reported greater daily intakes of food energy, most nutrients, vegetables and milk, and lower intakes of added sugars, soda and fruit drinks ${ }^{12}$. Middle-school students with access to snack bar foods consumed significantly fewer F\&V servings compared with elementary-school 
students who only received NSLP meals ${ }^{13}$. Among students followed for two years from elementary into middle school, where they had access to snack bars, servings of fruit, regular vegetables and milk decreased, while servings of high-fat vegetables and sweetened beverages increased ${ }^{14}$, further supporting the influence of the school food environment on consumption.

Some states and school districts have tried to improve the foods available in school food environments ${ }^{15}$. The present report describes the impact of local school food policy changes on lunch consumption in three middle schools in Harris County, Texas.

\section{Methods}

Three middle schools (approximately 2790 6th-8th grade students; 48\% free/reduced-price lunch; 61\% Hispanic, 34\% white, 3\% African American, 2\% Asian/other) in one school district in Harris County, Texas, participated. Data on student lunch consumption and daily snack bar sales data were available for two consecutive school years. During the 2001-02 school year, the three schools had participated as control condition schools in a school-based intervention ${ }^{16}$ during which the students completed lunch food records. Following this school year, the Food Service Director decided to implement local policy changes to remove snack chips, candy, sweet desserts and sweetened beverages from all of the district middle-school snack bars, and to remove VMs from the cafeterias for the 2002-03 school year. He invited the researchers to continue assessing student consumption, and offered the use of point-of-service (POS) machine electronic data files with daily snack bar sales for both years. Both studies were approved by the Institutional Review Board at Baylor College of Medicine. All parents received information about the study and were notified that their child could assent or refuse to provide anonymous lunch consumption data.

During both years, students who gave assent completed anonymous lunch food records in the cafeteria immediately after eating lunch, which maximised accuracy of report ${ }^{17}$. The second year of data collection used the methods from the intervention study. Trained data collectors selected one or two different tables of students at each lunch period and asked students to complete the anonymous food records. The data collectors showed the students how to record the foods eaten on the food records: listing each food on a separate line, indicating how many servings were eaten, and identifying the source of each food (school lunch, snack bar, home, vending, other source). This method of food record data collection has been shown to be valid in previous research ${ }^{18}$. To enhance student interest, study pencils were distributed to participating students during the first year and student names were entered into a weekly raffle for a \$25 gift card in the second year.

The food records were entered into Nutrition Data Systems (version 4.2; Nutrition Coordinating Center, University of Minnesota, Minneapolis, MN, USA) to obtain energy, nutrients and servings of food, using algorithms developed for a previous study ${ }^{19}$. The following food groups were obtained from the NDS output: fruit/juice, vegetables, high-fat vegetables, milk, total sweetened beverages, soft drinks (also included in total sweetened beverages), candy, cakes and pies, and snack chips.

The POS purchase machines provided an electronic data file of daily snack bar food sales. The cafeteria workers keyed in the appropriate item sold. These workers received no special training and no quality control studies were conducted. This was the method used during the intervention year, and was continued for the second year of data collection. The following items were used in analyses: sweetened beverages, fruit and vegetables, chips, milk, ice cream and sweets. Descriptions of the POS key labels by category are presented in Table 1 . These food groupings were chosen to correspond to the food groups from the dietary recall output and were related to study hypotheses. The number of VMs was assessed in each school by the data collector. The school principals were responsible for vending and sales data were not available.

Two datasets were of primary interest: self-reported lunch food records and POS data. Servings from selfreported food records consisted of an average of each nutrient and food group per student over a period of one week. POS sales were calculated as the percentage of total purchases in each category per week, because no data on consumption of these items were available. For each week, item-specific servings purchased were summed, divided by all applicable servings, and then multiplied by 100. A series of independent $t$-tests was applied to

Table 1 Point-of-service (POS) sales category labels with key descriptions

\begin{tabular}{ll}
\hline Category & Description of POS keys \\
\hline Ice cream & Blue Bell novelty, yoghurt cup, fruit parfait, ice cream pint (2 keys) \\
$\begin{array}{l}\text { Sweetened beverages } \\
\text { Chips }\end{array}$ & $\begin{array}{l}\text { Chips, snacks } \\
\text { Cakes/cookies }\end{array}$ \\
$\begin{array}{l}\text { Cinnamon roll, dessert, Crispito, cookies, Nutrigrain bar, Pop tart, Candy Snickers } \\
\text { Cruit, juice \& vegetables } \\
\text { Chef salad, small chef salad, vegetable/fruit, baked potato, breakfast juice, lettuce, fresh fruit, } \\
\text { vegetable (9 keys), fruit (8 keys), juice }\end{array}$ \\
Milk (3 keys), Nesquick (chocolate) milk
\end{tabular}


self-reported food record data by food source to investigate policy (pre and post) differences in total lunch consumption and differences in consumption by meal source (NSLP, snack bar, vending, other) after the policy change.

Time series analysis was used to assess the impact of the policy change on snack bar sales, using the standard autoregressive integrated moving average (ARIMA) model with the transfer function model ${ }^{20-22}$. The effects of policy changes were modelled by indicator variables and the structure of the policy change function determined the shape of the impact over time on the series under consideration. The main focus was testing whether and by how much the policy change altered the mean level of the series. Time series analysis was used because this method allows the identification of patterns within the data represented by the ordering of the observations while accounting for relationships in the data due to time. The ability of traditional methods is severely restricted when accounting for the relationship due to time, which is generally modelled as autocorrelations, trends and seasonal variations.

In intervention time series analysis, characteristic properties of changes of time series can be investigated by introducing a separate function. Different types of intervention such as permanent or temporary, sudden or gradual can be modelled and the level of the time series following the intervention is compared with the level of the series before the intervention. The effects of interventions or policy changes are modelled by indicator variables and the structure of the intervention function determines the shape of the impact over time on the series under consideration. Thus, the response series is assumed to be the sum of an ARIMA noise or 'background' series and an intervention function. Generally, the form of the intervention transfer function is identified by hypothesis. For example, we may expect that daily purchase of fruit, juice and vegetables $(\mathrm{F} \& \mathrm{~V})$ will increase sharply during the early periods of the policy change and then the effect will gradually decrease, but a residual permanent effect will remain after this declining period. However, in practice, we may know little about the exact form of the transfer function, and therefore we also evaluated the shape of the intervention empirically. Since the policy change in year 2 was permanent, a step function intervention analysis is most appropriate. Thus, in this study we focused on testing whether the policy change altered the level of the series, and if so, by how much.

Data before the policy change were used to identify the univariate ARIMA models for the time series noise processes for each snack bar item (sweetened beverages, F\&V, chips, milk, ice cream (not removed) and sweets). It was assumed that the same time series model for the time series noise process applied to both pre- and post-policy change data and that the only change was assumed to stem from that change.
To develop appropriate ARIMA models for the noise process, the Box-Jenkins iterative approach was followed and involved three stages: (1) model identification, (2) model estimation, and (3) model checking ${ }^{20}$. The $\operatorname{ARIMA}(p, d, q)$ model included three model specification parameters that detailed the time-related autocorrelation ( $p)$, partial autocorrelations $(d)$ and averaging process $(q)^{20,22}$. Diagnostic checks, including graphical procedures, were performed in the course of model building. To find a plausible set of ARIMA models, autocorrelation, partial autocorrelation and inverse autocorrelation functions were examined. The residuals of the model were checked for autocorrelation and normality. Akaike's Information Criterion and the Bayesian Information Criterion were used for the goodness-of-fit criterion and the chi-square test of the Ljung-Box-Pierce statistics. Model adequacy was also tested. When these conditions were met within acceptable bounds, the model was used to assess the effects of the policy change.

\section{Results}

There were 2205 self-reported food records for year 1 and 5268 for year 2 . In year 1 , the data collectors were only in the schools about $50 \%$ of the time. The district had an exclusive contract with a national beverage company, and individual principals determined the number of both beverage and snack food VMs. In year 1, the three schools had 21 VMs; $86 \%$ were beverage. The number of machines increased to 42 during year 2, of which $83 \%$ were beverage. During the summer of 2002, beverage VMs were removed from the school cafeterias. Many were placed in the hallways outside the cafeterias by the gyms.

Food and nutrient intake per student (mean and standard deviation) and percentage attributable to specific meal sources are shown in Table 2. A statistically significant impact of the policy change was observed for several nutrients and food groups between years. Intakes of saturated fat, vitamin A, calcium, sodium and milk were significantly higher, whereas servings of vegetables, sweetened beverages and soft drinks (a subset of sweetened beverages) were significantly lower, in the second year after the policy change.

More than half $(56-72 \%)$ of all nutrients consumed during the first year were attributable to the NSLP meals. NSLP meals were the major source (51-88\%) of fruit/juice, vegetable, high-fat vegetables, grains and milk consumption. Most servings of sweetened beverages (72\%), soft drinks (80.1\%) and candy (39\%) came from VMs, whereas most servings of snack chips (41\%) were obtained from the snack bar and vending (31\%). Most servings of cakes and cookies came from home (47\%).

There were some significant changes in the distributions after the policy change. The proportions of energy, protein, fat, fibre, iron, calcium, sodium and cake/cookies 
Table 2 Yearly group means and standard deviation (SD) of daily measures per student, with percentage of mean measures from each location: National School Lunch Program (NSLP), snack bar, vending and home

\begin{tabular}{|c|c|c|c|c|c|c|c|c|c|c|}
\hline & \multicolumn{5}{|c|}{ Year 2001-02 } & \multicolumn{5}{|c|}{ Year 2002-03 } \\
\hline & $\begin{array}{l}\text { Daily mean } \\
\text { (SD) }\end{array}$ & $\begin{array}{c}\text { NLSP } \\
(\%)\end{array}$ & $\begin{array}{c}\text { Snack bar } \\
(\%)\end{array}$ & $\begin{array}{c}\text { Vending } \\
(\%)\end{array}$ & $\begin{array}{c}\text { Home† } \\
(\%)\end{array}$ & $\begin{array}{l}\text { Daily mean } \\
\text { (SD) }\end{array}$ & $\begin{array}{l}\text { NLSP } \\
(\%)\end{array}$ & $\begin{array}{c}\text { Snack bar } \\
(\%)\end{array}$ & $\begin{array}{c}\text { Vending } \\
(\%)\end{array}$ & $\begin{array}{c}\text { Home } \\
(\%)\end{array}$ \\
\hline \multicolumn{11}{|l|}{ Nutrients } \\
\hline Energy (kcal) & $630(76)$ & $53.0^{*}$ & 24.2 & 11.9 & 11.0 & $685(84)$ & 60.3 & 20.6 & 11.5 & 7.6 \\
\hline Protein $(\mathrm{g})$ & $22.2(4.0)$ & $63.4^{*}$ & 26.8 & 1.2 & 8.7 & $23.9(3.1)$ & 71.2 & 20.0 & 3.0 & 5.8 \\
\hline Fat $(\mathrm{g})$ & $26.3(3.4)$ & $55.9^{\star}$ & 29.0 & 3.7 & 11.4 & $27.9(2.8)$ & 65.5 & 21.5 & 4.9 & 8.1 \\
\hline SFA (g) & $9.0(1.6)^{*}$ & 57.7 & 28.7 & 3.1 & 10.6 & $10.1(1.1)$ & 66.0 & 23.4 & 3.8 & 6.8 \\
\hline Fibre (g) & $3.7(0.7)$ & $61.5^{*}$ & 22.5 & 4.1 & 11.9 & $4.3(1.1)$ & 69.0 & 15.0 & 7.8 & 8.2 \\
\hline Vitamin A (RE) & $151(55.5)^{\star *}$ & 72.2 & 19.3 & $0.5^{*}$ & $8.0^{*}$ & $207(39.8)$ & 76.5 & 18.5 & 0.9 & 4.1 \\
\hline Vitamin C (mg) & $13.9(5.0)$ & 68.4 & 18.2 & 3.1 & 10.3 & $14.8(3.2)$ & 69.6 & 13.9 & 7.2 & 9.3 \\
\hline Iron (mg) & $3.4(0.7)$ & $58.1^{*}$ & 25.6 & 4.7 & 11.6 & $3.7(0.4)$ & 67.1 & 19.1 & 6.5 & 7.2 \\
\hline Calcium (mg) & $292(88)^{\star *}$ & $66.3^{*}$ & 22.8 & 2.7 & $8.2^{*}$ & $386(79)$ & 74.3 & 18.9 & 2.4 & 4.4 \\
\hline Sodium (mg) & $1020(167)^{\star}$ & $58.0^{*}$ & 26.9 & 3.4 & 11.8 & $1169(150)$ & 66.0 & 21.5 & 5.3 & 7.3 \\
\hline \multicolumn{11}{|l|}{ Servings } \\
\hline Fruit/juice & $0.32(0.25)$ & 87.4 & 6.4 & $0.0^{\star \star}$ & 6.2 & $0.36(0.30)$ & 84.9 & 5.6 & 1.2 & 8.3 \\
\hline Vegetables & $0.30(0.12)^{*}$ & 83.2 & $16.4^{*}$ & 0.0 & $0.5^{*}$ & $0.20(0.09)$ & 93.6 & 4.2 & 0.2 & 2.0 \\
\hline High-fat vegetables & $0.05(0.10)$ & 75.6 & 24.4 & 0.0 & 0.0 & $0.15(0.19)$ & 89.1 & 9.1 & 0.1 & 1.7 \\
\hline Milk (oz) & $2.44(1.41)^{\star *}$ & 88.3 & 8.8 & 0.0 & 2.9 & $4.40(1.92)$ & 92.3 & 6.1 & 0.1 & 1.5 \\
\hline Sweetened beverages (oz) & $5.43(3.13)^{\star}$ & $9.2^{*}$ & 13.1 & 71.5 & $6.1^{\star \star \star}$ & $3.54(1.68)$ & 3.8 & 6.4 & 77.5 & 12.4 \\
\hline Sweetened soft drinks (oz) & $4.76(3.05)^{*}$ & $5.2^{*}$ & $7.6^{\star}$ & 80.1 & $3.9^{* *}$ & $2.65(1.26)$ & 2.6 & 2.4 & 86.2 & 8.9 \\
\hline Candy & $0.09(0.06)$ & 20.4 & $24.3^{\star \star *}$ & $39.2^{*}$ & $16.2^{*}$ & $0.07(0.05)$ & 13.3 & 3.2 & 56.2 & 27.3 \\
\hline Cakes, cookies, etc. & $0.11(0.11)$ & $24.0^{*}$ & 7.4 & 21.6 & 47.1 & $0.09(0.09)$ & 40.1 & 9.1 & 13.1 & 37.7 \\
\hline Snack chips & $0.21(0.13)$ & 10.0 & $41.2^{\star \star}$ & $31.1^{*}$ & 17.7 & $0.20(0.11)$ & 12.1 & 20.2 & 46.9 & 20.8 \\
\hline
\end{tabular}

SFA - saturated fatty acids; RE - retinol equivalents.

Results from independent $t$-tests of differences for daily mean values, and percentage of meal sources, between school years are significantly different: ${ }^{*}, P<0.05 ;{ }^{* *}, P<0.01 ;{ }^{* * *}, P<0.001$ (independent $t$-tests used because the mix of students is different between years).

$\dagger$ 'Home' location includes 'other'.

were significantly higher from the NSLP meal in the second year. The proportion of sweetened beverages and soft drinks from the NSLP meals was significantly lower after the policy change. In the snack bar, the percentage of vegetables declined from 16.4 to $4.2 \%$, but it increased from home/other sources (0.5 to 2.0\%). Soft drinks declined from 7.6 to $2.4 \%$. Candy consumption declined from 24.3 to $3.2 \%$ in the snack bar and increased from 39.2 to $56.2 \%$ from vending. Snack bar snack chips declined from 41.2 to $20.2 \%$. At the same time, vending snack chips increased from 31.1 to $46.9 \%$.

Other vending changes included an increase in vitamin A and fruit/juice servings. Significant increases from home/other sources were noted for sweetened beverage (6.1 to $12.4 \%$ ) and soft drinks (3.9 to 8.9\%) consumption. Home sources of vitamin $\mathrm{A}$ and calcium decreased significantly.
Time series analyses assessed the impact of the policy change on the following snack food items: chips, ice cream, sweetened beverages, milk, sweets and F\&V (Table 3). Figure 1 indicates that the policy change abruptly and permanently decreased the percentage of chips sold in year 2 by 1.83 percentage points. Ice cream, as a percentage of sales, increased significantly by 1.47 points after the policy change (Fig. 2). Sales of sweetened beverages, milk, sweets and F\&V were not statistically significant between the two years, indicating no difference after the policy change (figures not shown).

\section{Discussion}

The main objective of this study was to identify the impact of school food policy changes on student dietary behaviours and POS sales data. The main food and

Table 3 Results from time series analyses of point-of-service sales: autoregressive integrated moving average (ARIMA) model specification and corresponding model coefficient, standard error (SE) and coefficient test statistics

\begin{tabular}{|c|c|c|c|c|c|}
\hline \multirow[b]{2}{*}{ Item } & \multirow{2}{*}{$\begin{array}{l}\text { ARIMA model } \\
\text { specification }\end{array}$} & \multirow{2}{*}{$\begin{array}{l}\text { Model coefficient } \\
\text { (SE) }\end{array}$} & \multirow[b]{2}{*}{ Statistics } & \multicolumn{2}{|c|}{$\begin{array}{l}\text { Percentage of total weekly sales, } \\
\text { mean (standard deviation) }\end{array}$} \\
\hline & & & & Year 1 & Year 2 \\
\hline Chips & $\operatorname{ARIMA}(0,1,2)$ & $-1.83(0.34)$ & $t=-5.32, P<0.001$ & $2.65(1.38)$ & $0.02(0.03)$ \\
\hline Ice cream & $\operatorname{ARIMA}(0,0,1)$ & $1.47(0.13)$ & $t=11.58, P<0.001$ & $0.7(0.32)$ & $1.43(0.92)$ \\
\hline Fruit, juice and vegetables & $\operatorname{ARIMA}(0,1,1)$ & $-0.12(3.33)$ & $t=-0.04, P=0.970$ & $11.27(7.91)$ & $1.42(3.42)$ \\
\hline Milk & $\operatorname{ARIMA}(0,0,3)$ & $0.027(0.028)$ & $t=0.98, P=0.327$ & $0.06(0.08)$ & $0.05(0.06)$ \\
\hline Sweets & $\operatorname{ARIMA}(0,0,0)$ & $0.022(0.014)$ & $t=1.63, P=0.103$ & $0.09(0.16)$ & $0.11(0.07)$ \\
\hline Sweetened beverages & $\operatorname{ARIMA}(0,1,1)$ & $0.80(0.51)$ & $t=1.57, P=0.116$ & $1.56(1.28)$ & $1.54(0.89)$ \\
\hline
\end{tabular}




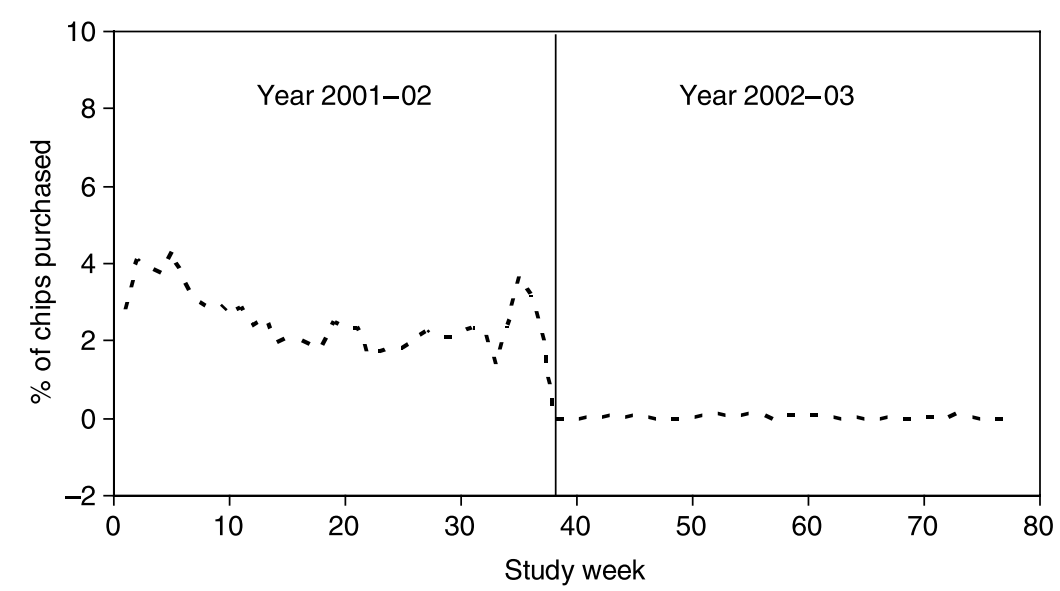

Fig. 1 Time series plot of the weekly average percentage of total servings purchased attributable to chips before (year 2001-02) and after (year 2002-03) the policy change

nutrients evaluated were those related to the US Department of Agriculture NSLP meal guidelines (energy, protein, fat, saturated fat, vitamins A and $\mathrm{C}$, iron, calcium and sodium) and the foods potentially impacted by the policy change (sweetened beverages, soft drinks, high-fat salty and sweet snacks and desserts, ice cream, F\&V and milk).

The school food policy change was captured in the student individual intakes, the sources of those foods and beverages and by the POS data. The overall increases in energy (although not statistically significant), protein, fat, fibre, iron and sodium may reflect increased participation in the NSLP meals as a consequence of reduced snack bar selections. The increases in vitamin A and calcium can be explained by the increase in milk (which is fortified with vitamin A) during the second year. Although there was a decline in sweetened beverage consumption in the second year, there was a small increase in the proportion of sweetened beverages and soft drinks from VMs. The number of beverage VMs doubled, and there was some increase in the VM source of candy and snack chips as reported in the lunch food records between the two years of the study. Sales data from the VMs were not available, and it would be important to capture these data in future research.

Although the proportion of candy purchased from the snack bar declined significantly in year 2 , there was no overall reduction in consumption. The proportion of candy intake from vending increased from $39.2 \%$ in year 1 to $56.2 \%$ in year 2 . Overall snack chip consumption also did not decline, but there was a significant reduction in purchases from the snack bar. More snack chips were purchased from vending in year 2 (31.1 to 46.9\%). These results suggest that there was shifting in the source of some food items, i.e. more use of VMs and more sweetened beverages from home, after the policy change. The reduction in vegetable consumption is more difficult to explain, but could be related to the frequency of menu offerings of high-fat vegetables like French fries, which increased during year 2 although not significantly. One finding that is difficult to explain is the reported consumption of sweetened beverages, snack chips and candy from the snack bar, although they were not sold there. Because the students self-reported the source of the foods eaten, there could have been student errors in reporting source. More time allotted to data collectors who checked records for accuracy might improve validity of the lunch records.

Although the POS data revealed significant declines in snack chip sales, supporting the policy change, the time series analysis also revealed a significant increase in the proportion of ice cream sales during year 2 (Fig. 2), an increase not seen in the dietary records. Perhaps students purchased more ice cream in place of snack chips. The individual cafeteria managers were responsible for ordering snack bar items from the general food inventory list. This food order likely reflects the managers' personal preferences and items that have the most sales. These data suggest that there could be some compensation for the lack of snack chips as the students consumed more of another snack like ice cream. This could be a significant issue if the goal of the intervention was to reduce the kcal available in the snack bar. However, altering portion size of a product, e.g. substituting a smaller size bag for a larger size chip bag, could achieve kcal reduction.

The POS data for the remaining food groups sweetened beverages, sweets, milk and F\&V - revealed no significant differences in sales across the two years, despite the individual data showing overall increased milk consumption and declines in sweetened beverage and vegetable consumption. This lack of congruence between the POS data and individual consumption may highlight one limitation of the data. The individual student data were from lunch food records from a daily convenience sample of students who volunteered to complete the lunch food records. However, the POS data represented all food and beverage items that were 


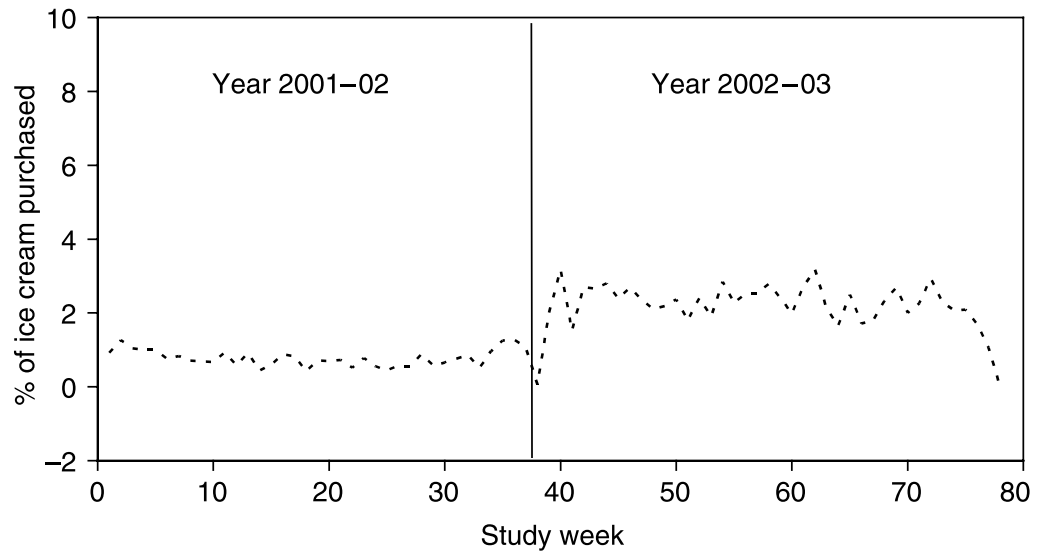

Fig. 2 Time series plot of the weekly average percentage of total servings purchased attributable to ice cream before (year 2001-02) and after (year 2002-03) the policy change

sold during the two school years. The daily student sample may not have captured the usual dietary patterns that are represented by the daily sales record. The food groupings may have been too broad, limiting the ability to detect differences. The lack of vending sales data is another limitation. Both beverage and snack food machines were available in all schools, and the lunch record data suggest that more students were obtaining beverages and snacks from these machines during the second year.

Further delineation of the reasons for the purchases of snack bar and vending foods by students eligible for the free/reduced-price meal is needed. There may be a need for more positive advertising/marketing of the NSLP meal to students and staff. Previous research has identified that poor attitudes towards the NSLP meals represent a serious barrier to NSLP participation ${ }^{23}$. Because of the critical need for nutrients during growth in middle-school students, this should be a priority area for further research.

A recent study used direct observation to identify the impact of competitive foods on secondary-school students' consumption in two high schools and one middle school ${ }^{24}$. Per transaction, competitive foods accounted for 51 to $81 \%$ of total energy, a little higher than the $35 \%$ of total energy from non-NSLP foods found in this current study (Table 1). In this sample of 6th-8th grade students, F\&V consumption was about 0.62 serving per lunch, slightly lower than the 0.82 serving reported for 5 th grade middle-school students consuming only the NSLP meal ${ }^{13}$. This probably reflects the lower F\&V consumption of the students who ate in the snack bar or used VMs.

All of the student data were from self-report, which is limited by memory and ability to estimate portion size. There is no demographic information associated with the individual food records, and no comparison between those who did and did not complete food records can be calculated. Therefore generalisability is limited. The records were completed during the lunch period, which increased confidence in the validity of the self-report ${ }^{17}$. The POS data only included sales from the snack bar and did not reflect purchases from VMs or foods brought from home or outside the school. Some snack bar items might not have been available on some days, but this information was not available. Other limitations include the possibility that the wrong keys were selected for certain foods, e.g. the cake key selected instead of the snack chip key. The food service workers were performing their normal jobs and the lines often became long and loud, possibly influencing accurate data entry. For more consistent and accurate data, paid research staff could be employed as checkers. A validation study documenting the validity of the POS data as a surrogate measure of individual dietary consumption would be an important area for future research. Although the time series method is limited in that it might not incorporate information on covariates as well as traditional methods, covariates for the time series analysis were not used in this study. A more in-depth discussion of the application of time series analysis to this type of data is beyond the scope of this paper; interested readers are referred elsewhere en $^{20,22}$.

Finally, changes that occur in dietary consumption in school may not reflect dietary changes over a 24-hour period. There could be compensation outside school, with students consuming more of the foods that were limited in school. Capturing 24-hour dietary intake would have helped to answer this concern. Future research on changes in school food environments should include 24-hour food recalls.

There are several key findings from this study. School food policy changes were related to observable changes in individual student dietary behaviour and in POS sales data after the policy change, suggesting that environmental change can lead to individual dietary change associated with the particular environment. However, these data also suggest that school food changes need to be implemented in all food environments, so that 
students cannot change source of foods and thereby make no dietary changes.

\section{Acknowledgements}

This work is a publication of the US Department of Agriculture (USDA)/Agricultural Research Service (ARS) Children's Nutrition Research Center, Department of Pediatrics, Baylor College of Medicine and Texas Children's Hospital, Houston, Texas. This project has been funded in part by federal funds from the USDA/Economic Research Service and the USDA/ARS under Cooperative Agreements No. 143-3AEL-2-80121 and 58-6250-6001. The contents of this publication do not necessarily reflect the views or policies of the USDA, nor does mention of trade names, commercial products or organisations imply endorsement by the US Government. This work was also supported by a grant CA88511 from the National Cancer Institute (to K.W.C.). The authors thank the Pasadena Independent School District for their participation in this study.

\section{References}

1 Devaney B, Gordon A, Burghardt J. The School Nutrition Dietary Assessment Study: Dietary Intakes of Program Participants and Nonparticipants. Princeton, NJ: Mathematica Policy Research Inc., 1993.

2 Gordon AR, Devaney BL, Burghardt JA. Dietary effects of the National School Lunch Program and the School Breakfast Program. American Journal of Clinical Nutrition 1995; 61: 221S-31S.

3 Hedley AA, Ogden CL, Johnson CL, Carroll MD, Curtin LR, Flegal KM. Prevalence of overweight and obesity among US children, adolescents, and adults, 1999-2002. Journal of the American Medical Association 2004; 291: 2847-50.

4 US General Accounting Office (GAO). Competitive Foods are Available in Many Schools; Actions Taken to Restrict Them Differ by State and Locality. Report GAO-04-673. Washington, DC: GAO, 2004.

5 Bandura A. Social Foundations for Thought and Action: A Social Cognitive Theory. Englewood Cliffs, NJ: Prentice Hall, 1986.

6 Perry CL, Bishop DB, Taylor GL, Davis M, Story M, Gray C, et al. A randomized school trial of environmental strategies to encourage fruit and vegetable consumption among children. Health Education E Behavior 2004; 31: 65-76.

7 US Department of Agriculture (USDA). National School Lunch Program: Nutrition Standards for Lunches and Menu Planning Methods ( 7 CFR 210.10). Report 63 FR 9721. Alexandria, VA: USDA, Food and Nutrition Service, 1997.

8 Fox MK, Crepinsek MK, Connor P, Battaglia M. (SNDA) School Nutrition Dietary Assessment Study - II (Summary Findings). Report CN-01-SNDAII. Alexandria, VA: US Department of Agriculture, Food and Nutrition Service, Office of Analysis, Nutrition and Evaluation, April 2001.

9 French SA, Story M, Fulkerson JA, Gerlach AF. Food environment in secondary schools: a la carte, vending machines, and food policies and practices. American Journal of Public Health 2003; 93: 1161-7.

10 Kubik MY, Lytle LA, Hannan PJ, Perry CL, Story M. The association of the school food environment with dietary behaviors of young adolescents. American Journal of Public Health 2003; 93: 1168-73.

11 Ho C, Gould RA, Jensen LN, Kiser SJ, Mozar A, Jensen JB. Evaluation of the nutrient content of school, snack and vending lunch of junior high students. School Food Service Research Review 1991; 15: 85-90.

12 Gleason P, Suitor C. Children's Diets in the Mid-1990's: Dietary Intake and Its Relationship with School Meal Participation. Report CN-01-CD1. Alexandria, VA: US Department of Agriculture, Food and Nutrition Service, Office of Analysis, Nutrition and Evaluation, January 2001.

13 Cullen KW, Eagan J, Baranowski T, Owens E, de Moor C. Effect of a la carte and snack bar foods at school on children's lunchtime intake of fruits and vegetables. Journal of the American Dietetic Association 2000; 100: 1482-6.

14 Cullen KW, Zakeri I. Fruits, vegetables, milk, and sweetened beverages consumption and access to a la carte/snack bar meals at school. American Journal of Public Health 2004; 94: $463-7$.

15 Malloy C, Johanson J, Wootan M. The School Foods Tool Kit. Washington, DC: Center for Science in the Public Interest, 2003.

16 Cullen KW, Thompson VJ, Watson K, Nicklas T. Marketing fruit and vegetables to middle school students: formative assessment results. Journal of Child Nutrition \& Management 2005; 29(2). Available at http://d.cs.schoolnutrition.org/newsroom/jcnm/05fall/cullen/index.asp

17 Baxter SD, Thompson WO, Davis HC, Johnson MH. Impact of gender, ethnicity, meal component, and time interval between eating and reporting on accuracy of fourth-graders' self-reports of school lunch. Journal of the American Dietetic Association 1997; 97: 1293-8.

18 Domel SB, Baranowski T, Davis H, Leonard SB, Riley P, Baranowski J. Fruit and vegetable food frequencies by fourth and fifth grade students: validity and reliability. Journal of the American College of Nutrition 1994; 13: 1-7.

19 Cullen KW, Himes JH, Baranowski T, Pettit J, Stevens M, Slawson DL, et al. Validity and reliability of a behavior-based food coding system for measuring fruit, 100\% fruit juice, vegetable, and sweetened beverage consumption: results from the Girls Health Enrichment Multisite Studies. Preventive Medicine 2004; 38(Suppl.): S24-33.

20 Box GEP, Jenkins GM, Reinsel GC. Time Series Analysis, Forecasting, and Control. Englewood Cliffs, NJ: Prentice Hall, 1994.

21 Box GEP, Tiao GC. ARIMA: intervention model for ozone data. Journal of the American Statistical Association 1975; 70: $70-5$.

22 McCleary R, Hay JRA. Applied Time Series Analysis for Social Sciences. Newbury Park, CA: Sage, 1980.

23 Meyer M, Conklin M, Lewis J, Marshak J, Cousin S, et al. Barriers to healthy nutrition environment in public school middle grades. Journal of Child Nutrition \& Management 2001; 25: 66-71.

24 Cohen R, Ramani AK, Nogales R, Ohls J, Sinclair M. Measuring Competitive Foods in Schools: A Point of Sales Approach. Report CN-04-CFMPR. Alexandria, VA: US Department of Agriculture, Food and Nutrition Service, Office of Analysis, Nutrition and Evaluation, 2004. 